\title{
PRINCIPAIS MOTIVAÇÕES DOS ALUNOS DESCENDENTES DE JAPONESES NO APRENDIZADO DA LÍNGUA JAPONESA
}

Clara Yoshiko Hori Takigawa ${ }^{1}$, Mitiko Hori ${ }^{2}$

${ }^{1}$ Engenharia de Produção - FEPP - UNOESTE. ${ }^{2}$ Especialização em ensino e aprendizagem de língua japonesa como língua estrangeira - USP. E-MAIL: clarahori@unoeste.br

\section{RESUMO}

No processo de aprendizagem da língua estrangeira (LE), a intensidade e a qualidade do envolvimento do aluno estão estreitamente relacionadas à sua motivação. Neste sentido, o presente estudo é uma pesquisa qualitativa e quantitativa que teve como objetivo descrever as motivações dos alunos descentes de japoneses no estudo da língua japonesa de um Centro de Estudo de Línguas de Presidente Prudente-SP através da aplicação de um questionário com os alunos do último estágio do curso. Constatou-se que eles estudam motivados pela cultura de seus antecedentes e são motivados pelos seus familiares. No entanto, foi verificado que o curso é o único contato dos alunos com a cultura japonesa fora do ambiente familiar, o que coloca este Centro de Estudo no rol das entidades que contribuem para a preservação desta cultura na cidade e região.

Palavras-chave: Motivação. Aprendizagem. Língua japonesa. Centro de Estudo de Línguas. Descendentes de japoneses.

\section{INTRODUÇÃO}

Atualmente, cada vez mais e com mais intensidade as crianças e os adolescentes participam de forma ativa dos avanços que a sociedade moderna apresenta, seja através dos meios de comunicação, seja através das interações com os diferentes grupos sociais que as circundam. Nesse sentindo, conhecer uma língua estrangeira (LE doravante) é muito importante devido ao multiculturalismo e ao plurilinguismo da sociedade na qual estamos inseridos.

Os alunos motivados no processo de aprendizagem podem chegar ao conhecimento da LE apesar de suas dificuldades, mas sem motivação o suficiente, mesmo os alunos com habilidades notáveis, não chegam ao máximo de seu potencial e não conseguem atingir objetivos a longo prazo (DÖRNYEI, 2011).

Nesse sentido, conhecer o que proporciona o despertar do interesse em outra língua e o que incentiva e estimula o aluno a superar todos os desafios do aprendizado é de suma importância para o ensino de uma LE.

Neste contexto, este trabalho tem como objetivo apresentar e analisar as origens das principais motivações dos alunos descendentes de japoneses de um Centro de Estudo de Línguas 
de Presidente Prudente-SP do último estágio do curso (3o estágio-nível II) em relação ao aprendizado da língua japonesa.

O conhecimento desse perfil motivacional poderá possibilitar a criação de um ambiente de ensino e aprendizagem que estimule de forma prazerosa uma maior participação dos alunos durante o maior tempo possível, assim como poderá ajudar na elaboração de uma estratégia de divulgação para o curso junto às comunidades existentes propiciando o aumento de alunos interessados em cursar a língua japonesa.

\section{METODOLOGIA}

Esta pesquisa é um estudo de caso, com análises qualitativas e quantitativas.

Como instrumento de coleta de dados, utilizou-se um questionário misto elaborado pelas autoras. Este estudo não teve o intuito de generalizar os resultados, mas sim, compreender o funcionamento de um determinado grupo em um determinado contexto.

Quanto ao conteúdo, os assuntos versam sobre as influências, hábitos, desejos e opiniões relacionados à aprendizagem da língua japonesa, abordando os fatores internos e externos que ativam a motivação do aluno neste processo, bem como se essa motivação é direta ou indireta.

Os alunos participantes desta pesquisa são os 09 alunos descendentes de japoneses dos 16 alunos regulamente matriculados no 3o estágio-nível II (último estágio do curso), com faixa etária de 14 a 17 anos de idade.

\section{RESULTADOS}

Através do questionário traçou-se o perfil dos alunos participantes da pesquisa, assim como verificou-se as principais motivações dos alunos descendentes de japoneses no aprendizado da língua japonesa, como apresentado a seguir.

Quando perguntados por que eles estudam a língua japonesa, as razões que se destacaram foram: "porque sou descendente e tenho de falar"; "para conhecer a cultura japonesa (etiqueta, comida, festividades, esportes, entre outros)"; e "para falar com meus avós / familiares / parentes japoneses" (Quadro 1). 
QUADRO 1. Porque você estuda a língua japonesa? (escolha as três maiores razões porque você estuda japonês, assinalando em ordem crescente de 1 para a maior motivação, 2 e 3 de acordo com a ordem de motivação.).

\begin{tabular}{|c|c|c|}
\hline $\begin{array}{c}\text { Grau do } \\
\text { fator } \\
\text { motivacional }\end{array}$ & Razões para estudar a língua japonesa & $\begin{array}{c}\text { Número } \\
\text { de } \\
\text { alunos }\end{array}$ \\
\hline \multirow{4}{*}{ 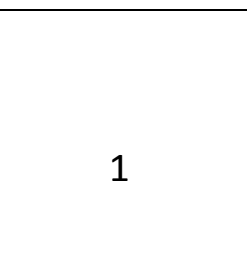 } & Porque sou descendente e tenho de falar & 03 \\
\hline & $\begin{array}{l}\text { Para conhecer a cultura japonesa (etiqueta, comida, } \\
\text { festividades, esportes, entre outros) }\end{array}$ & 03 \\
\hline & Para falar com meus avós / familiares / parentes japoneses & 02 \\
\hline & Para utilizar no trabalho futuramente & 01 \\
\hline \multirow{4}{*}{2} & Para conseguir ler manga e anime & 02 \\
\hline & $\begin{array}{l}\text { Para conhecer a cultura japonesa (etiqueta, comida, } \\
\text { festividades, esportes, entre outros) }\end{array}$ & 02 \\
\hline & Para falar com meus avós / familiares / parentes japoneses & 01 \\
\hline & Porque sou descendente e tenho de falar & 01 \\
\hline \multirow{4}{*}{3} & Porque sou descendente e tenho de falar & 02 \\
\hline & Para falar com meus avós / familiares / parentes japoneses & 02 \\
\hline & Para conseguir ler manga e anime & 01 \\
\hline & Para utilizar no trabalho futuramente & 01 \\
\hline
\end{tabular}

Para analisar as demais respostas do questionário, foi elaborado o Quadro 2, o qual contém um resumo das quantidades numéricas de alunos que responderam sim, não ou mais ou menos nas perguntas realizadas.

QUADRO 2. Quantificação das respostas obtidas nas perguntas do questionário.

\begin{tabular}{|l|c|c|c|c|}
\hline \multicolumn{1}{|c|}{ Questões } & \multicolumn{2}{|c|}{$\begin{array}{c}\text { No de alunos que } \\
\text { responderam }\end{array}$} & \multirow{2}{*}{\begin{tabular}{c} 
Mais \\
ou \\
\cline { 2 - 4 }
\end{tabular}} & Sotal \\
menos & Não & - & 09 \\
\hline $\begin{array}{l}\text { Você teve influência dos amigos para começar a estudar a } \\
\text { língua japonesa? }\end{array}$ & 03 & 06 & - & \\
\hline $\begin{array}{l}\text { Você está cursando japonês para ou por fazer parte de } \\
\text { algum grupo da comunidade (taiko, odori, grupo de } \\
\text { igreja, e outros)? }\end{array}$ & 01 & 08 & - & 09 \\
\hline $\begin{array}{l}\text { Seus pais ou responsáveis incentivam você a estudar o } \\
\text { idioma japonês? }\end{array}$ & 07 & 02 & - & 09 \\
\hline Você já foi ou já morou no Japão? & 04 & 05 & - & 09 \\
\hline $\begin{array}{l}\text { Você já prestou Exame de Proficiência em Língua } \\
\text { Japonesa (Noryoku Shiken)? }\end{array}$ & 0 & 09 & - & 09 \\
\hline Usa ou estuda japonês fora da sala de aula? & 07 & 02 & - & 09 \\
\hline
\end{tabular}




\begin{tabular}{|l|c|c|c|c|}
\hline Você gosta de fazer tarefa de japonês? & 03 & 06 & - & 09 \\
\hline Você acessa a internet para pesquisar sobre o Japão? & 05 & 04 & - & 09 \\
\hline Você usa a língua japonesa? & 05 & 04 & - & 09 \\
\hline Você é incentivado a usar o japonês? & 06 & 03 & - & 09 \\
\hline Você gosta de vir para a aula de japonês? & 02 & 0 & 06 & 08 \\
\hline $\begin{array}{l}\text { Você gosta dos colegas de sala da aula do curso de } \\
\text { japonês? }\end{array}$ & 04 & 0 & 04 & 08 \\
\hline Você gosta do livro de japonês utilizado em sala de aula? & 04 & 0 & 03 & 08 \\
\hline $\begin{array}{l}\text { Você gosta das atividades extras (origami, vídeo, } \\
\text { exposição, desenho, entre outros) dadas no curso? }\end{array}$ & 05 & 0 & 03 & 08 \\
\hline Você gosta da escola E.E. Monsenhor Sarrion? & 01 & 01 & 06 & 08 \\
\hline $\begin{array}{l}\text { Você acha que o aprendizado da língua japonesa será útil } \\
\text { para você futuramente? }\end{array}$ & 05 & 03 & 0 & 08 \\
\hline Você acha difícil aprender a língua japonesa? & 02 & 01 & 05 & 08 \\
\hline
\end{tabular}

Quando questionado se o aluno teve influência dos amigos para começar a estudar a língua japonesa, 06 participantes disseram que não tiveram influência dos amigos. $E$ quando perguntados ele está cursando japonês para ou por fazer parte de algum grupo da comunidade (taiko, odori, grupo de igreja, e outros), apenas 01 aluno respondeu a alternativa sim.

07 alunos participantes disseram que tem incentivo dos pais para estudar a língua japonesa, sendo que esse muitas vezes é dado através da utilização da língua em diálogos do cotidiano e em atividades de lazer da família.

Ao perguntar se o aluno já foi ou morou no Japão, dos 09 participantes, 04 já moraram no Japão, sendo que 02 deles moraram por 7 anos, 01 morou por 6 anos e 01 por 2 anos. Os 03 participantes que já moraram no Japão de 6 a 7 anos, disseram que desejam retornar para o Japão, pois gostam mais do Japão do que do Brasil e sentem muita saudade de lá.

Quando questionados para onde eles iriam se ganhassem uma viagem para o exterior, 07 escolheram a opção Japão justificando que gostariam de conhecer pessoalmente a cultura nipônica ou que gostariam de retornar para a "terra natal", e 02 alunos escolheram a opção Estados Unidos.

Ao perguntar se o aluno já prestou Exame de Proficiência em Língua Japonesa (Noryoku Shiken), foi constatado que nenhum aluno desta turma prestou esse exame. No entanto quando perguntados se gostariam de prestar o exame, apenas 03 participantes disseram que gostariam de prestar o exame para testar o seu nível de conhecimento no idioma e 06 participantes disseram que não gostariam de prestar o exame, sem justificar a resposta escolhida.

Quando perguntado se eles gostam de fazer a tarefa de japonês, 03 participantes responderam que gostam de fazer as tarefas que utilizam a conversação e 06 alunos responderam 
que não gostam de fazer as tarefas. No entanto, 05 participantes disseram que acessam a internet para pesquisar sobre a cultura, as cidades, a língua, a culinária e as curiosidades do Japão.

Quando questionados se os alunos usam ou estudam japonês fora da sala de aula, 07 participantes responderam afirmativamente e disseram que utilizam em média de 2 a 3 horas por semana e 02 participantes disseram que não possuem esse hábito.

E quando foi perguntado onde eles usam a língua japonesa as respostas citadas foram em casa e/ou na casa dos avós, com uma frequência diária através da utilização de vocabulário em japonês, ou seja, os alunos utilizam palavras em japonês no meio de frases em português, tal como, "Okasan, o gohan está pronto?" - "Mãe, o arroz (referindo-se a refeição) está pronto?".

Quando questionado se o aluno é incentivado a usar o japonês, 06 dos participantes disseram que são incentivados a falar, a ler e a ouvir através de conversas com familiares, leituras de mangá, assistindo anime e ouvindo músicas. E quando foi perguntado o que mais incentiva o aluno a continuar estudando o japonês, 05 participantes responderam que é o apoio dado pela sua família e 04 participantes responderam que é pelo fato de serem descendentes de japoneses e desejarem aprender mais sobre a sua antecedência.

Nas questões sobre os fatores motivacionais externos dos alunos, ou seja, as perguntas eram relacionadas ao ambiente de aprendizagem, houve 01 aluno que deixou todas essas questões em branco, sendo assim, as análises a partir de agora serão consideradas com população pesquisada de 08 alunos.

Ao perguntar se o aluno gosta de vir para a aula de japonês, 02 participantes disseram que sim, justificando que a aula é interessante e a sensei (professora) é legal. 06 participantes disseram que gostam mais ou menos de vir à aula, justificando que se sentem cansados devido ao excesso de compromissos diários que possuem, com a escola regular, curso técnico de ensino médio e curso pré-vestibular.

Quando foi perguntado se o aluno gosta dos colegas de sala de aula do curso de japonês, 04 alunos participantes disseram que sim, justificando que os colegas da turma são legais. 04 alunos disseram que gostam mais ou menos dos colegas de sala, pois não possuem muito contato, convivência e amizade com eles.

Em relação ao livro de japonês utilizado em sala de aula, 04 alunos participantes responderam que gostam do livro, pois é de fácil entendimento e possui ótimos exemplos. 03 participantes responderam que gostam mais ou menos do livro, pois apresenta muitas atividades 
diferentes das quais há algumas que eles não gostam de fazer. Houve 01 aluno participante que deixou essa pergunta em branco.

Quando questionou se os alunos gostam de atividades extras (origami, vídeo, desenho, entre outros) dadas no curso, 05 participantes disseram que gostam destas atividades, pois acreditam que essas atividades colaboram com o seu aprendizado e que é algo diferente do habitual visto em sala de aula. No entanto, 03 participantes disseram que gostam mais ou menos destas atividades, pois apesar de serem interessantes ocupam parte do período da aula.

Ao perguntar se o aluno gosta da escola no qual o curso é ofertado, 01 participante respondeu que sim justificando que a escola possui qualidade de ensino. 06 participantes responderam que gostam mais ou menos ou não gostam da escola devido à escola possuir uma direção muito rigorosa e exigente. Apenas 01 participante disse que não gosta da escola devido à sua localização ser longe de sua residência.

Quando perguntado ao aluno se ele acha que o aprendizado da língua japonesa será útil para ele futuramente, 05 participantes disseram que o aprendizado da língua japonesa será útil sim, principalmente se precisarem conversar ou forem ao Japão. Os demais alunos participantes responderam que acham que o aprendizado da língua japonesa será mais ou menos útil para eles, justificando que o futuro é imprevisível.

Na última questão do questionário foi perguntado se o aluno acha difícil aprender a língua japonesa, 01 participante disse que não acha difícil o aprendizado comparando com o aprendizado da língua portuguesa. 05 participantes disseram que acham mais ou menos difícil o aprendizado devido à complexidade dos ideogramas e de determinados assuntos serem "confusos" devido aos traços dos ideogramas, as variedades de formas de contagem, entre outros. São essas as mesmas justificativas dos 02 alunos que disseram que acham sim o aprendizado da língua japonesa difícil.

\section{DISCUSSÃO}

As respostas das primeiras perguntas demonstram um fato muito interessante, pois se constata que os alunos não são influenciados pelos amigos e nem pelo ambiente no qual eles estão inseridos. Neste grupo de alunos pesquisado, a maior influência que eles possuem é proveniente da própria família.

Curiosamente os 02 alunos que disseram não serem incentivados pelos pais a estudar o japonês, ambos já moraram no Japão por 7 anos, são do sexo masculino e possuem 17 anos de 
idade. Eles estudam a língua japonesa por iniciativa própria para não "esquecê-la" e ambos demonstraram no questionário o desejo de retornar ao Japão.

Uma informação curiosa levantada nesta pesquisa foi a considerável quantidade de alunos na turma que já moraram no Japão e que fazem o curso para se aprimorar e não esquecer o idioma aprendido, visando retornar futuramente ao Japão.

O exame de proficiência em língua japonesa (com reconhecimento internacional) não é um fator motivacional no aprendizado da língua japonesa, talvez seja ocasionado pelo desconhecimento da importância desta titulação.

Para os alunos descendentes de japoneses, a utilização das palavras japonesas no seu cotidiano é algo muito natural, sendo assim, o aumento da variedade de vocabulário durante o curso pode ser um fator motivador no aprendizado da língua japonesa. Essa afinidade/empatia com a língua estudada pode ser considerada outro fator motivacional no aprendizado da LE.

\section{CONCLUSÕES}

Através do estudo realizado conclui-se que os alunos pesquisados estudam a língua japonesa motivados pela sua etnia, pela utilização diária da língua com os seus familiares e também para ter um maior contato e conhecimento da cultura de seus ascendentes, visto que eles não possuem contato com a cultura japonesa através dos clubes, grupos, associações, entidades religiosas, e outros lugares com concentração de descendentes de japoneses, que de alguma forma ajudam a preservar a cultura nipônica.

Desta forma, acreditamos que o curso de língua japonesa deste Centro pode ser também considerado como um meio de preservação desta cultura na cidade e região, pois para esses alunos o curso é a única fonte externa ao do seio familiar, de conhecimento relacionado à sua ascendência.

Neste contexto, a motivação desses alunos pode ser classificada de acordo com a teoria de Dörnyei (1994) no Nível 1, o nível mais geral do construto da motivação, que refere-se à dimensão social e está relacionada fortemente à cultura da LE. E segundo a classificação de Schütz (2003) na qual a motivação pode ser direta ou indireta, a análise das respostas obtidas no questionário nos leva a concluir que esses alunos possuem motivação direta no aprendizado.

Ainda segundo Schütz (2003), a motivação também pode ser classificada como interna ou externa, e os resultados da pesquisa demonstram que o principal fator interno ativador da 
motivação dos alunos é a necessidade natural de se relacionar com as pessoas do seu ambiente de modo que permita a interação com o ambiente, sua participação e atuação.

Como fator externo ativador da motivação, temos o incentivo da família para o aluno fazer o curso que é visto por eles, como um importante fator motivacional na aprendizagem da LE. Em contrapartida as amizades, a perspectiva de este aprendizado ser um diferencial no mercado de trabalho futuramente e o Exame de Proficiência em Língua Japonesa (Noryoku Shiken) não são fatores motivacionais no aprendizado da língua japonesa, pois influenciam muito pouco neste processo.

Um fator que influencia de modo negativo no aprendizado da língua japonesa nesta turma é o cansaço e a falta de tempo para dedicação devido à sobrecarga de atividades diárias desses alunos.

Os alunos que nunca foram ao Japão também demonstraram o desejo de um dia conhecer a "terra do sol nascente".

A motivação do aluno em relação ao ambiente de aprendizagem pode ser considerada um fenômeno complexo e dependente de uma diversidade de fatores, inclusive conceituais que o aluno possui neste momento específico da vida.

A elaboração desta pesquisa constituiu um momento de reflexão sobre os vários aspectos motivacionais do processo de ensino e aprendizagem da língua japonesa no curso deste Centro de Estudo de Línguas de Presidente Prudente-SP, proporcionando um melhor entendimento dos interesses e dos objetivos dos alunos pesquisados quanto ao que os motivam nesta caminhada.

\section{REFERÊNCIAS}

ANDRADE, M. R. M. (Orgs). Afetividade e emoções no ensino/aprendizagem de línguas: múltiplos olhares. v.18. Campinas: Pontes Editores, 2011.

CAVENAGHI, Ana Raquel Abelha. Uma perspectiva autodeterminada da motivação para aprender língua estrangeira no contexto escolar. Ciências e cognição. v.14 (2). p. 248-261, 2009. Disponível em: <http://pepsic.bvsalud.org/scielo.php?pid=S1806-58212009000200017\&script=sci_arttext >. Acesso em: 16 abr. 2012.

DÖRNYEI, Z. Teaching and researching motivation. 2ed. Harlow: Longman/Pearson, 2011. Motivation and motivating in the foreign language classroom. The Modern Language Journal. v.78. p.273-284, 1994.

GARDNER, R. C.; LAMBERT, W. E. Social psychology and second language learning: the role of attitudes and motivation. London: Richard Clay (The Chaucer Press) Ltd., 1985. 
SCHÜTZ, Ricardo. Motivação e desmotivação no aprendizado de línguas. English Made in Brasil. 2003. Disponível em: <http://www.sk.com.br/sk-motiv.html>. Acesso em: 16 abr.2012.

CALLEGARI, Marília Oliveira Vasques. Motivação, ensino e aprendizagem: caminhos possíveis. Análise e intervenção num Centro de Estudos de línguas de São Paulo. 2008. 230f. Tese (Doutorado em Educação). Universidade de São Paulo, São Paulo, 2000.

MARINS, Ida Maria Morales. O contexto social na motivação de crianças aprendizes de uma língua estrangeira. 2005. 113 f. Dissertação (Mestrado em Letras: linguística aplicada). Universidade Católica de Pelotas, Pelotas, 2005. 